\title{
Corrigendum: Genome-wide profiling of PRC1 and PRC2 Polycomb chromatin binding in Drosophila melanogaster
}

Bas Tolhuis, Inhua Muijrers, Elzo de Wit, Hans Teunissen, Wendy Talhout, Bas van Steensel \& Maarten van Lohuizen

Nature Genetics 38, 694-699 (2006); published online 20 April 2006; corrected after print 9 June 2006

In the version of this article initially published, the order of the first three authors was incorrect. The correct order should be Bas Tolhuis, Elzo de Wit, Inhua Muijrers. This error has been corrected in the PDF version of the article.

\section{Erratum: Functions of microRNAs and related small RNAs in plants}

Allison C Mallory \& Hervé Vaucheret

Nature Genetics 38, S31-S36 (2006); published online 30 May 2006; corrected after print 9 June 2006

In the version of this article initially published, two labels depicting methylation $\left(\mathrm{CH}_{3}\right)$ were inadvertently omitted from the miRNA duplex shown below HEN1 in Figure 1. In addition, the arcs accompanying the pie chart in Figure 2 were misaligned. Corrected figures are shown here. These errors have been corrected in the HTML and PDF versions of the article.
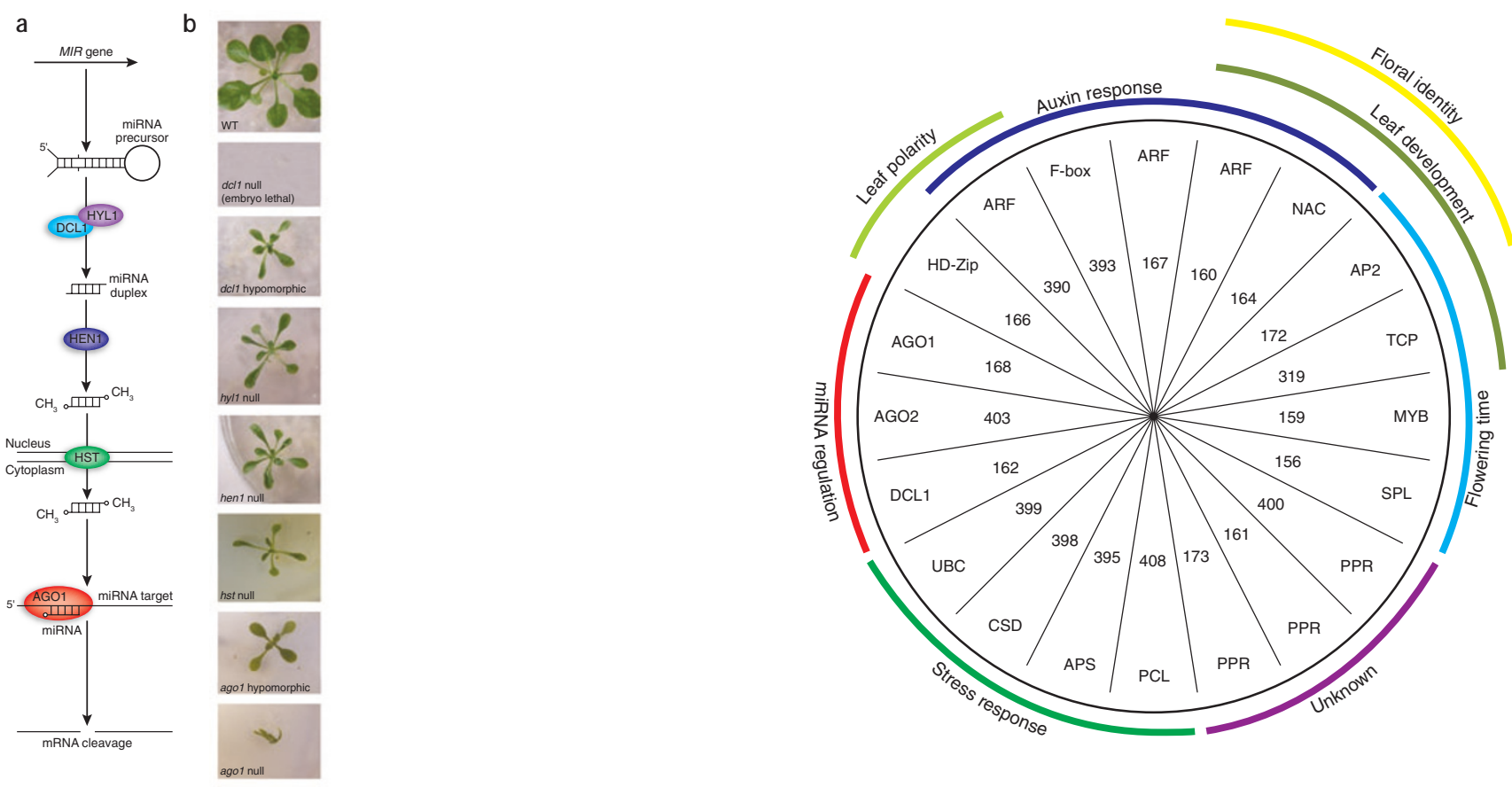

\section{Erratum: Touching Base}

Nature Genetics 38, 613 (2006); corrected after print 16 June 2006.

In the version of this article initially published, text was omitted at the end of the paragraph. This error has been corrected in the PDF version of the article. The corrected text is shown here.

\section{Publishing sequence traces}

Following our request for tips for publishing high-quality figures incorporating sequence traces, Tom Schwei and Anne Stover at DNASTAR pointed out that researchers using either a Mac or a PC can cut and paste from their Lasergene SeqMan sequence alignment software into Adobe Illustrator and get very high quality EPS files for publication. This particular sequence viewer allows stretching and zooming in on the sequence traces and

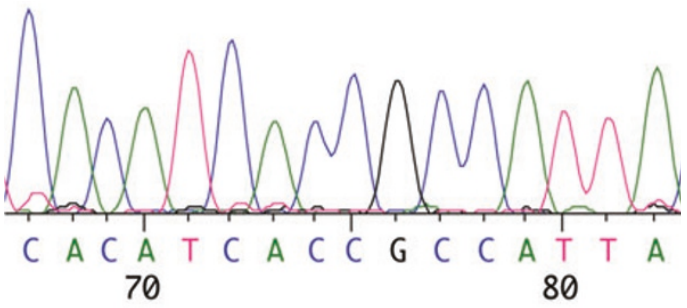
as a consequence it is important initially to paste the clip into a vector graphics program like Illustrator and not a photo editing program like Adobe Photoshop. We have determined that there are also open-source and freely available trace viewers and vector graphics programs for those who want to work out how to use them. We would be pleased to continue the discussion of publishing optimal traces on our blog (http://blogs.nature.com/ng/freeassociation/). 